\title{
Design and testing of a GPS/CSM collar prototype to combat cattle rustling
}

\author{
Francesco M. Tangorra, ${ }^{1}$ Aldo Calcante, ${ }^{2}$ Stefano Nava, ${ }^{1}$ Gabriele Marchesi, ${ }^{1}$ \\ Massimo Lazzari ${ }^{1}$
}

\author{
'Scienze Veterinarie per la Salute, la Produzione Animale e la Sicurezza Alimentare, Università di \\ Milano; ${ }^{2}$ Scienze Agrarie e Ambientali - Produzione, Territorio, Agroenergia, Università di Milano, \\ Italy
}

\begin{abstract}
Rustling is an age-old practice that was widespread in Italy until the first half of the $20^{\text {th }}$ century. Today, incidents of cattle rustling are again being reported. However, the problem is not only found in Italy. It is also becoming a plague for ranchers in the US and is still rampant in East Africa. In Italy, the cattle rustling phenomena have usually been limited through the direct control of the herdsmen. Global positioning system (GPS) and geographic information system (GIS) combined technologies are increasingly applied for tracking and monitoring livestock with greater spatial and temporal resolution. However, so far, no case studies of the use of GPS technology to combat cattle rustling have been reported in the literature. The aim of this research was to develop a GPS/GSM (global system for mobile communication) collar, using commercial hardware and implementing a specific software [ARVAshepherd 1.0; ARVAtec Srl, Rescaldina (MI), Italy] to track animals' movements outside their grazing area and to signal when animals are straying outside virtual perimeters. A phase I study was conducted from January to June 2011 to build the GPS/GSM collar and to assess its performances in terms of GPS accuracy and precision, while a phase II study was conducted in July 2011 to test the GPS collar under real-life operating conditions. The static GPS positioning error achieved a circular error probable (50\%) and horizontal 95\% accuracy of $1.462 \mathrm{~m}$ and $4.501 \mathrm{~m}$, respectively. This is comparable with values obtained by other authors in static tests of a commercial GPS collar for grazing studies. In field tests, the system was able to identify the incorrect position of the cattle and the warning messages were sent promptly to the farmer, continuing until the animals had been repositioned inside the fence, thus highlighting the potential of the GPS/GSM collar as an anti-theft system.
\end{abstract}

Correspondence: Francesco M. Tangorra, Scienze Veterinarie per la Salute, la Produzione Animale e la Sicurezza Alimentare, Università di Milano, via Celoria 10, 20133 Milano, Italy. E-mail: francesco.tangorra@unimi.it

Key words: GPS, animal tracking, theft detection, virtual fencing.

Received for publication: 18 June 2013.

Accepted for publication: 4 September 2013.

(C) Copyright F.M. Tangorra et al., 2013

Licensee PAGEPress, Italy

Journal of Agricultural Engineering 2013; XLIV:e10

doi:10.4081/jae.2013.e10

This article is distributed under the terms of the Creative Commons Attribution Noncommercial License (by-nc 3.0) which permits any noncommercial use, distribution, and reproduction in any medium, provided the original author(s) and source are credited.

\section{Introduction}

Rustling refers to the act of stealing livestock, especially cattle and sheep, from a farm or a pasture. Rustling was very widespread in Italian grazing areas until the first half of the $20^{\text {th }}$ century, but recent decades have seen a gradual decline following changes in farming techniques which led to a reduction in the number of pastured herds (Bassignana, 2005). In the last few years, however, livestock theft has been reappearing throughout Italy. The national law enforcement agency estimated that, during 2008, thousands of heads of cattle were stolen and sent to illegal slaughterhouses. Cattle rustling is an offense that goes beyond the direct interests of the agricultural sector and affects the whole community. More specifically, it affects product quality and public health. Cattle theft is an international problem that is growing because of the current economic recession. Cattle rustling is becoming a plague for US ranchers as reported more and more frequently by media and cattle producers' associations. During 2005 , the theft of cattle and calves in the US totalled $0.6 \%$ and $0.5 \%$, respectively, of non-predator losses. These percentages, though small, represent losses of over 14 million US dollars (NASS, 2006). Cattle theft is still rampant in some parts of East Africa among the cross-border communities between Kenya and adjoining areas of Uganda, Sudan, Ethiopia and Somalia (Siror et al., 2009). In Italy, the solution adopted to combat cattle rustling is direct control by the herdsmen. However, such surveillance is not always feasible, especially in grazing areas far from the farm centre. Global positioning system (GPS) and geographic information system (GIS) combined technologies provide new opportunities for large-scale livestock monitoring, such as in alpine pasture farming. Moreover, transmitting data via satellite communications or via GSM enables remote data-download, reducing the need for frequent recapture of animals for collar data retrieval.

The use of GPS-collar receivers for tracking animal movement is common in wildlife studies (Moen et al., 1996; Rempel and Rodgers, 1997; Sibbald and Gordon, 2001) and recently GPS and GIS technologies have been used to assess livestock grazing behaviour and management with greater spatial and temporal resolution (Turner et al., 2000; Ganskopp, 2001; Agouridis et al., 2004; Barbari et al., 2006; Clark et al., 2006; Pandey et al., 2009; Thurner et al., 2011). Anderson (2000) developed a virtual fence through the use of GPS collars to reduce labour costs associated with fence construction in rotational grazing. A review of the evolution of virtual fencing has been recently published (Umstatter, 2011).

Case studies on the use of GPS technology to combat cattle rustling have not been reported in literature. Siror et al. (2009) proposed a solution based mainly on the use of radio frequency identification to address the problem of cattle rustling in East Africa.

The aim of this research was to develop a GPS/GSM collar using 
commercial hardware and to implement a specific software [ARVAshepherd 1.0; ARVAtec Srl, Rescaldina (MI), Italy] in order to reduce cattle rustling. The research activities were financed by a local association of Romagnola cattle breeders interested in developing the use of pasture in a north-eastern area of the Apennines (Associazione Provinciale Allevatori, Forlì, Italy).

\section{Materials and methods}

\section{Project overview}

A phase I study was conducted from January to June 2011 to build a GPS/GSM collar to combat cattle rustling [GPS-anti cattle rustling (GPS-ACT)]. This phase involved the following steps: i) choice of hardware components and their assembly; ii) implementation of a software for managing cartography and data recording by a GPS receiver; iii) implementation of a short message service (SMS) interface to send and receive SMS between the GPS collar and the cattle farmer; and iv) static tests to determine 2D-horizontal accuracy and precision of the GPS receiver.

A phase II study was conducted in July 2011 to test the GPS-ACT prototype under real-life operating conditions. This phase entailed geo-referencing of grazing areas and fitting five collar prototypes on the same number of cows of a grazing herd to track their location in the pasture area and assess the potential of the system as an anti-theft solution.

\section{Phase I study}

\section{GPS/GSM collar design: hardware and software components}

Major hardware components of the GPS-ACT included a GPS receiver, a quad-band GSM antenna, a rechargeable Li-Ion buffer battery (3.7 $\mathrm{V}, 0.85 \mathrm{Ah}$ ) and an external sealed rechargeable backup NiMH battery. The estimated absorption of the system is $0.15 \mathrm{~W}$. A $3.6 \mathrm{~V}$ and 14000 mAh battery provides an estimated autonomy of $340 \mathrm{~h}$ (approx. 14 days).

The hardware backbone contains: quad-band (850/900/1800/1900 $\mathrm{MHz}$ ) GSM/GPRS engine; L1 C/A code 20-channel GPS receiver (with EGNOS correction) based on an SiRF Star IV chip set and ARM7/TDMI CPU core; the device integrated an SIM card reader and embedded micro-SD card reader (Figure 1).

The hardware layer components are supported by a standard configurable embedded firmware layer. Using an easy script-like command framework, all the device-relevant operation parameters (firmware update, data logging, alarm, tracking conditions, reports, communication channel parameters, geo-fencing conditions, etc.) can be defined. With the same script, it is also possible to set the GPS fixing calculation frequency (from $1 \mathrm{~s}$ to $1 \mathrm{~h}$ between two consecutive fixes).

The GPS/GSM antenna and the metal box containing both the device and the external power battery were attached to a leather collar (120 $\mathrm{cm}$ long, $10 \mathrm{~cm}$ wide) that allowed them to be fixed to the neck of the animal. The box was then coated with heat-sealing rubber to provide a smooth surface that was free of protrusions that could interfere with the shrubs and trees typical of the Apennine pastures. The rubber coating also ensured adequate protection from atmospheric elements and protected the device from accidental damage. The inner surface of the collar was lined with a closed-cell cross-linked polyethylene foam suitably shaped to provide a correct, comfortable grip on the animal's neck. The GPS/GSM antenna was fixed to the top of the collar for optimal reception of satellite signals (Figure 2).

The external battery and the device were connected through a metallic net placed around the collar (positioned between the leather collar and the polyethylene foam). In this way, if the collar was unfastened or tampered with (as could happen in case of cattle theft) the electric circuit would be interrupted and a warning message (SMS) sent to the cattle farmer.

The GPS-ACT calculated GPS positions differentially corrected in real-time using the European geostationary navigation overlay system (EGNOS).

Software for managing cartography and data recorded by GPS-ACT, and a SMS interface for sending/receiving SMS to/from the GPS-ACT were developed in collaboration with ARVAtec Srl.

The software tool ARVAshepherd 1.0 was developed in Delphi 7 language (Borland Corp., Austin, TX, USA) and was structured in three main parts.

A first section (Figure 3) was implemented for: i) importing shape files (land parcels), ECW files (aerial photographs), and raster graphic images from an external storage memory (USB pen drive or portable hard drive) without the need for an Internet connection; ii) drawing polygonal and circular virtual fences, and displaying their area, perimeter and number of vertices (for polygons) or area, circumference and radius (for circles); iii) calculating the real distance between points; iv) importing GPS coordinates.

Main features of the second section were: i) displaying virtual fences with their characteristics, such as shape (polygons or circles) and location (latitude and longitude of each vertex for polygons and the centre for circles); ii) erasing erroneously drawn virtual fences; iii) setting a

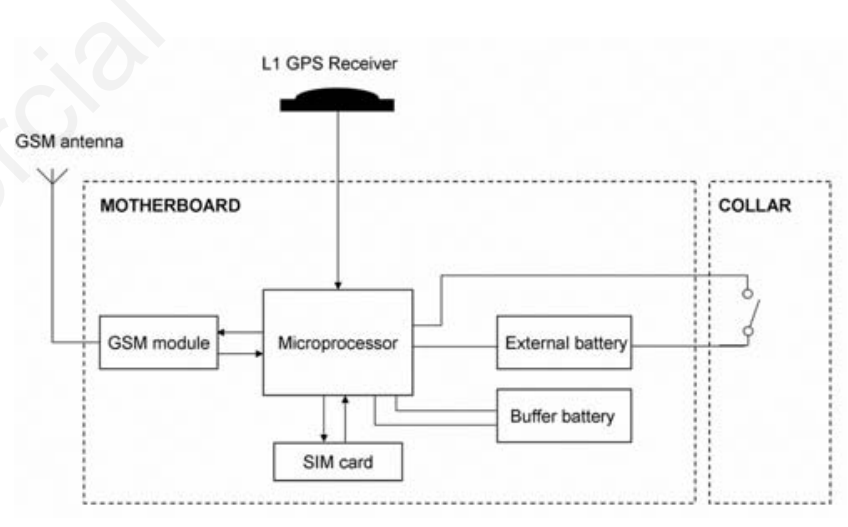

Figure 1. Block diagram of the global positioning system (GPS)anti cattle rustling.

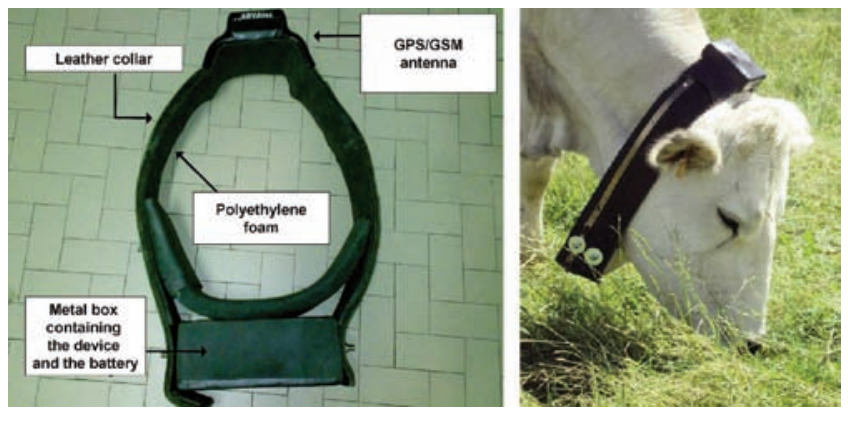

Figure 2. The assembled global positioning system (GPS)-anti cattle rustling and a cow with the antitheft system. GSM, global system for mobile communication. 
minimum of three mobile phone numbers to which warning messages would be sent in the case in which the GPS-ACT crossed the virtual fences or the GPS-ACT was tampered with. Note that the farmer can interact with the device telephonically and request the cow's GPS position; iv) setting pre-alert zones, outside the virtual fence, where no warning SMSs are sent. This function compensates for position errors of the GPS-ACT when the distance covered when trespassing from virtual fences is limited.

Both virtual fence coordinates and mobile phone numbers to contact in case of alarm are saved in a micro-SD memory connected to the device's motherboard.

The third section was implemented for the serial port setting when the GPS-ACT is connected by wire to PC for downloading GPS-fix data.

The SMS interface was developed to ensure the interaction between the cattle farmer and the GPS collar through sending and receiving SMS when: i) a cow wearing the GPS-ACT exited/entered the virtual fences; ii) GPS-ACT was unfastened or tampered with; iii) the external battery charge level was not sufficient (at $<10 \%$ charge levels, a specific message is automatically sent to the farmer); and iv) the cattle farmer calls to know the position of the GPS-ACT.

Whenever the GPS-ACT sent an SMS, date, time, grazing area, latitude, longitude, altitude, and external battery charge levels were displayed on the cattle farmer's mobile phone. A flowchart summarising the system operation is reported in Figure 4.

\section{Laboratory testing}

A GPS-ACT long-term static test was conducted at the Department of Agricultural and Environmental Sciences of the University of Milan, northern Italy. The test was performed to determine device accuracy and precision before the field test. The GPS-ACT was placed next to an active geodetic antenna of a base station belonging to the Department (ellipsoidal coordinates: latitude $45^{\circ} 28^{\prime} 34.828061$ ', longitude $9^{\circ} 13$ ' 36.911848 , altitude $174.10 \mathrm{~m}$ ) and equipped with an Ashtech GPS Receiver XII Z-12. The geodetic antenna is powered at $5 \mathrm{~V}$ and is able to receive L1 (1575.42 MHz) and L2 (1227.60 MHz) frequencies. The GPS-ACT was set to calculate GPS data at $30 \mathrm{~s}$ intervals during a test carried out from May $26^{\text {th }}$ to May $28^{\text {th }}, 2011$.

The 2D-horizontal accuracy of the GPS-ACT during the static test was examined using the guidelines established by the Institute of Navigation as outlined in ION STD 101: Recommended Test Procedures for GPS Receivers (ION, 1997). This manual is mainly based on US Department of Defense GPS specification documents and is the recommended protocol for performing static GPS accuracy tests (Stombaugh et al., 2002). The 2D-horizontal accuracy is defined as the distance between a point of known position and the barycentre of the GPS data recorded during the test.

The precision of the GPS-ACT during the static test was calculated using the following statistics: mean, CEP (circular error probable) or 50\%, 1 sigma (one standard deviation, 68\%), and R95 (horizontal 95\% accuracy). Moreover, data received from the satellites were used for the calculation of the dilution of precision (DOP) average value.

\section{Phase II study}

A GPS-ACT field test was conducted during July 2011 on a private farm at the barycentre of the GPS located in the Northern Apennines (latitude 43.810316, longitude 12.061403). The farm owns four contiguous grazing areas at altitudes within 1000 and $1200 \mathrm{~m}$ asl, for a total surface area of approximately 10 ha. While during winter the cows are kept inside a barn, from around June through to September, depending on weather conditions, livestock are put out to graze on pasture. The vertices of the pastures were determined using the differential global positioning system (DGPS) technology with post-processing correction to create virtual fences. The DGPS system consisted of two Topcon dual frequency GPS receivers (Topcon Corporation, Tokyo, Japan), one (Topcon Hiper Pro) used as a base station at the pasture border, and the other (Topcon GB 500) as a rover station. Due to land topography, a dwelling time of 2 min was set up for each point. Post processing of GPS data was carried out using Grafnav Lite software, ver. 6.03 (Waypoint Software, NovAtel Inc., Alberta, Canada). Corrected GPS data points were imported into ARVAshepherd (ARVAtec Srl) to rebuild the polygons of the grazing areas and to project them onto a satellite digital

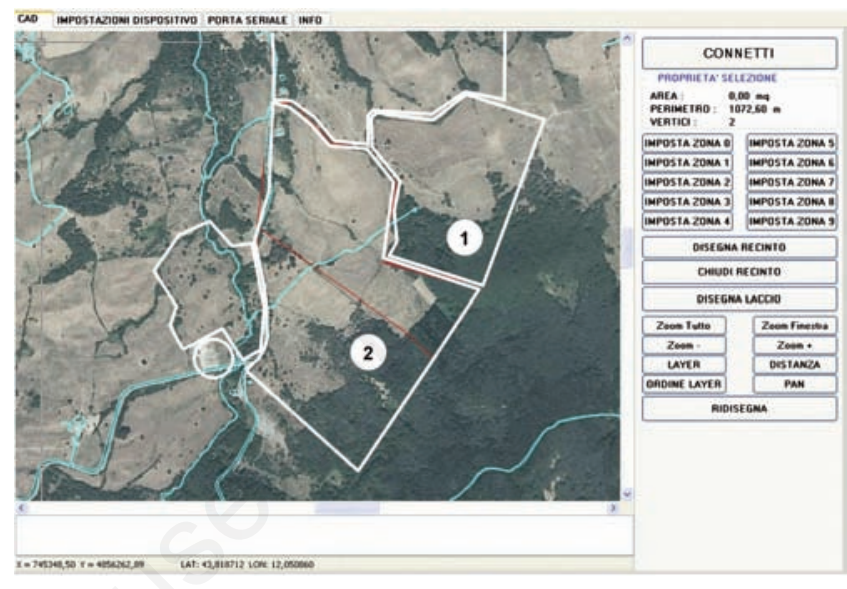

Figure 3. A software tool section (ARVAshepherd 1.0) developed for managing cartography and data calculated by global positioning system-anti cattle rustling. The numbered polygons indicate the virtual fences.

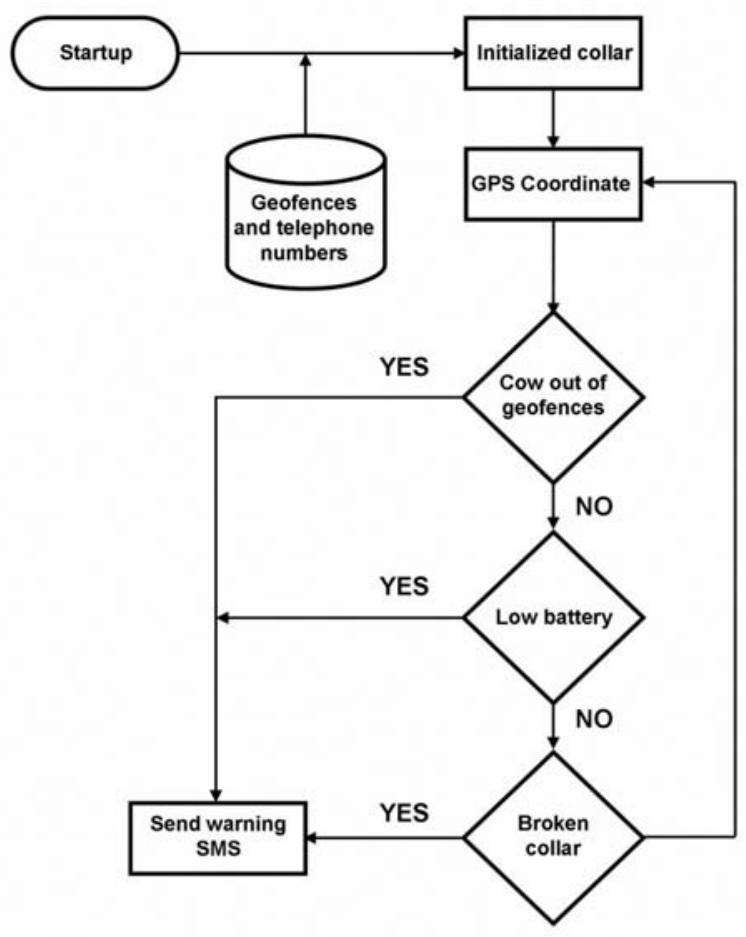

Figure 4. Global positioning system (GPS)-anti cattle rustling operating logic flow sheet. 
map geo-referenced according to World Geodetic System 1984 (WGS84) reference system. The same correct GPS data were uploaded into the GPS-ACT memory (micro-SD) and used to define the virtual fences. In this way, the virtual fence is superimposed on the physical fence creating the GPS-controlled barrier that cows may not trespass.

Five GPS-ACT were applied to the same number of multiparous dry cows of a grazing herd composed of 40 subjects (30 cows and 10 calves) to assess the ability of the GPS receiver to provide accurate animal position and to limit cattle rustling through sending warning messages to the farmer whenever the cow exited the virtual fence or the GPS-ACT was unfastened or broken, as happens in case of theft.

The GPS-ACTs were applied to the cows on July $24^{\text {th }} 2011$ and powered-up just prior to application. The GPS receivers were programmed to calculate a GPS fix every $60 \mathrm{~s}$. Only when the cow GPS position was located outside the virtual grazing, the SMS warning was sent to the farmer. On the contrary, because the device was not equipped with an internal memory, the GPS fix was immediately eliminated. Field tests were organised as follows: i) the 5 cows equipped with the GPS-ACT were brought outside of the fence in order to evaluate the reliability of the system in identifying incorrect positions; and ii) the system was removed from the neck of the cattle to verify the correct transmission of the warning signals.

\section{Results and discussion}

\section{Laboratory testing}

In the long-term static test, over $49 \mathrm{~h}$ of data, totalling approximately 5900 positions, were collected and downloaded to a notebook through the serial port. Figure 5 shows the horizontal scatter plot of the position error as regards to an active geodetic antenna of a base station with coordinates: $\mathrm{x}$ (easting) $=517735.95 \mathrm{~m}$ and $\mathrm{y}$ (northing) $=5035893.19 \mathrm{~m}$ (UTM-WGS84 Zone 32). With an average calculated accuracy of 1.030 $\mathrm{m}$ and a DOP of 1.4, the position measurements can be considered sufficiently accurate to satisfy all the most sensitive applications. Moreover, this GPS performance is consistent with the EGNOS correction applied. Within the designated time period, the static GPS positioning error achieved a mean, CEP (50\%), 1 sigma (68\%), and R95 (95\%) of $1.854 \mathrm{~m}, 1.462 \mathrm{~m}, 1.637 \mathrm{~m}$, and $4.501 \mathrm{~m}$, respectively. These values are comparable with those obtained by Agouridis et al. (2004) in open field static tests of a commercial GPS collar for grazing studies.

\section{Field testing}

Out of the four contiguous grazing areas of the farm, only Pastures 1 (1.77 ha) and 2 (3.77 ha) were used for the field test. Considering that the R95 value of the GPS positioning error calculated during the GPS-ACT static test was $4.501 \mathrm{~m}$, a buffer of $5 \mathrm{~m}$ around the virtual fences was used for the five collars. This buffer limited the number of erroneous warning messages sent from the collar. The grazing areas are characterised by open fields and areas covered by shrubs and trees that are not always accessible to the cattle. Theft simulations bringing every cow equipped with the GPS-ACT outside the virtual fence gave interesting results. The system was able to identify the incorrect position of all the cows and the warning messages were sent to the farmer every $5 \mathrm{~min}$ until the animals had been re-positioned inside the fence. Figure 6 shows the GPS points calculated by the five GPS-ACTs and projected on the ARVAshepherd 1.0 software interface.

Each message displayed date, time, grazing area, latitude, longitude, altitude, and internal and external battery charge levels. These data enabled the farmer to check the cows' position, warding off a potential danger or theft and verifying GPS collar function. Despite the fact that GSM coverage in the Northern Apennines is limited, no problem was encountered in sending or receiving SMS to or from the GPS collar. Only in one case did one of the GPS-ACT send an incorrect warning message (on $26^{\text {th }}$ July at 2.33 p.m.). The farmer subsequently found that, probably, the GPS receiver was subject to a high error of positioning $(>5 \mathrm{~m})$ that had incorrectly placed the cow outside the virtual fence.

The five GPS-ACT batteries ran out after approximately 14 days, as expected by the power consumption test. On July $6^{\text {th }}$, the farmer received the first warning message from one of the collars signalling a residual charge of external battery of $10 \%$. He received the other four alarms over the following $20 \mathrm{~h}$. The field test was re-started with

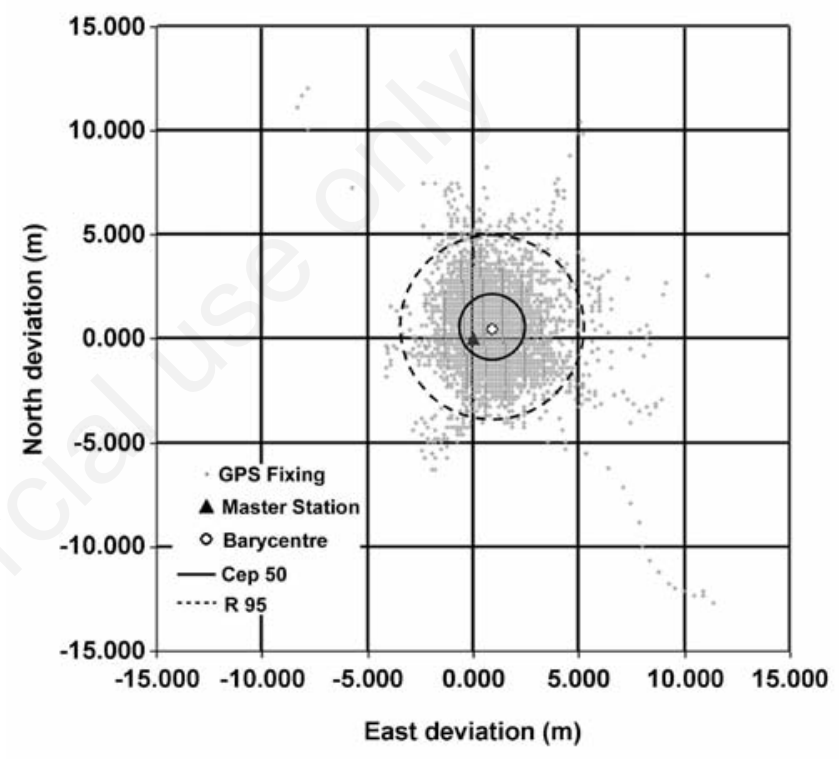

Figure 5. Horizontal scatter plot for long-term static positioning test. GPS, global positioning system; CEP, circular error probable; R95, horizontal 95\% accuracy.

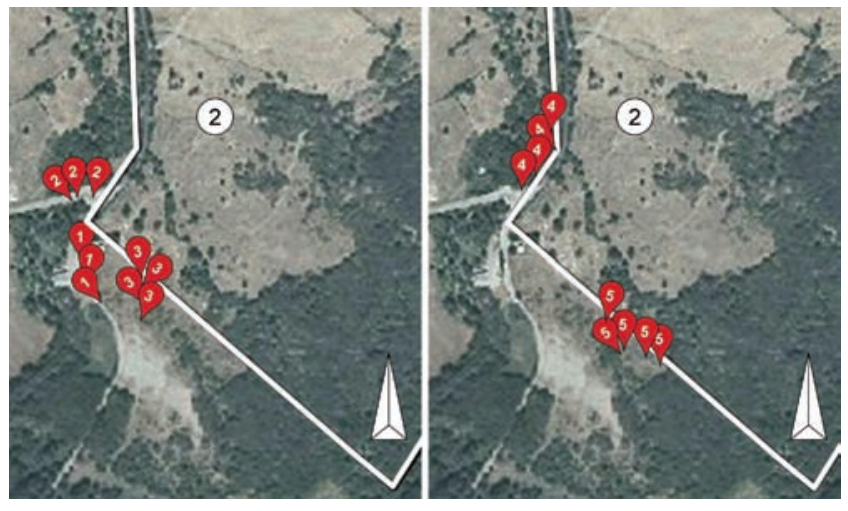

Figure 6. Global positioning system points related to cows brought outside the fence projected on the digital map interface of ARVAshepherd 1.0 software. 
Table 1. Comparison of the global positioning system (GPS)-anti cattle rustling with some available commercial and experimental GPS systems.

\begin{tabular}{|c|c|c|c|c|}
\hline $\begin{array}{l}\text { Device } \\
\text { classification }\end{array}$ & $\begin{array}{l}\text { Company/ } \\
\text { institution }\end{array}$ & $\begin{array}{l}\text { Product } \\
\text { name }\end{array}$ & $\begin{array}{l}\text { Approx. } \\
\text { weight, g }\end{array}$ & $\begin{array}{c}\text { Differential } \\
\text { correction }\end{array}$ \\
\hline Experimental & $\begin{array}{l}\text { University of Milan - ARVAtec Srl, Italy } \\
\text { Iowa State University, USA } \\
\text { US Department of Agriculture - Oregon State University, USA }\end{array}$ & $\begin{array}{l}\text { GPS-ACT } \\
\text { GPS HAWK } \\
\text { Clark ATS }\end{array}$ & $\begin{array}{c}2000 \\
3371 \\
990\end{array}$ & $\begin{array}{l}\text { EGNOS } \\
\text { WAAS } \\
\text { WAAS }\end{array}$ \\
\hline Commercial & $\begin{array}{l}\text { Lotek Wireless Inc., Canada } \\
\text { BlueSky Telemetry, Scotland } \\
\text { Telonics Inc., USA }\end{array}$ & $\begin{array}{l}\text { GPS Livestock } 3300 \\
\text { AGTRAX L6-118 (livestock tracking) } \\
\text { TGW } 4601 \text { (cattle) }\end{array}$ & $\begin{array}{c}950^{*} \\
470-720^{\circ} \\
1100-1200^{\#}\end{array}$ & $\begin{array}{l}\text { As option } \\
\text { Post-processing } \\
\text { Post-processing }\end{array}$ \\
\hline
\end{tabular}

GPS-ACT, global positioning system-anti cattle rustling; EGNOS, European geostationary navigation overlay service; HAWK; herd activity and well-being kit; WAAS, wide area augmentation system. *With light duty belt; 'excluding harness and depending on battery power pack; "with collar.

new batteries on the afternoon of $8^{\text {th }}$ July 2011 and continued for approximately another 14 days on Pasture 1 . Finally, we simulated 10 cattle rustling events by unfastening the GPS-ACT's collar from the cows inside the fence. In all cases, the warning messages were correctly received by the farmer. The inner lining of the GPS-ACT with a closed-cell cross-linked polyethylene foam ensured the collar had a good fit and no lesions were observed on the skin of the animal equipped with the collar during the field test. Moreover, no restrictions on the behavioural activities of the animal (grazing, lying, standing or walking) were observed. However, a longer field test for the entire grazing season from June through September is needed to confirm these preliminary observations.

\section{GPS-anti cattle rustling design and cost}

At the moment of writing, the manufacturing cost (included the feasibility study) for each of the five GPS-ACT prototypes was approximately 400 euro, whilst the cost for the software was estimated at 1000 euro. If the system is to be produced in a large number of pieces, it is reasonable to expect a reduction in price to approximately 250 euro for each piece. As reported by Clark et al. (2006) and Davis et al. (2011), several manufacturers market GPS collars for tracking animal movement patterns (i.e. Lotek Inc., BlueSky Telemetry, Telonics Inc., etc.) but commercial GPS tracking collars with remote data-access capabilities that are large enough for beef cattle cost approximately 2300 euro/unit plus the cost of software and any peripheral devices. Clark et al. (2006) developed an experimental low-cost (650 euro plus $2 \mathrm{~h}$ labour charges) GPS-based animal tracking system. More recently, an experimental low cost (390 euro plus $6 \mathrm{~h}$ labour charges) GPS herd activity and well-being kit (GPS HAWK) was developed by Davis et al. (2011) to monitor locomotion behaviour of cattle at high sampling frequency (recording interval time of $20 \mathrm{~s}$ ). The GPS-ACT was solid and sturdy and weighed $2.0 \mathrm{~kg}$ including the external backup battery, leather harness and padding foam. The high-frequency sampling (recording interval time of $60 \mathrm{~s}$ ) for anti-theft monitoring required a larger battery for the GPS-ACT making it heavier than the commercial collars but comparable to other experimental devices developed for monitoring animal behaviour at high sampling frequency, such as the GPS HAWK (Davis et al., 2011). For a $600 \mathrm{~kg}$ animal, this would only be $0.5 \%$ of body weight.

Table 1 compares the GPS-ACT to other commercial and experimental devices to be used with beef cattle.

\section{Conclusions}

The objective of this research was to develop a GPS/GSM collar for combating cattle rustling in extensive grazing areas. Results were satisfactory even if some aspects will have to be revised.

Field tests highlighted the potential of the GPS-ACT as an anti-theft system. When the cow wearing the GPS collar exited the virtual fences delimiting the grazing areas, an SMS displaying the main GPS data (date, time, grazing area, latitude, longitude and altitude) was sent to the farmer enabling him to check the cow's position and ward off a potential danger or theft. During field tests, the GPS-ACT has proved reliable and was able to identify: i) when cows were brought out of the virtual fence; and ii) any tampering with the collar. In conclusion, this can be considered to be an interesting prototype of an anti-theft system. Battery life was the most limiting factor of GPS-ACT function due to the high power consumption associated with the high frequency GPS sampling (60-s intervals) required by anti-theft monitoring. Further studies should be aimed at reducing the energy requirements of the GPS collar, for example, by integrating the device with photovoltaic cells positioned around the collar.

\section{References}

Agouridis C.T., Stombaugh T.S., Workman S.R., Koostra B. K., Edwards D.R., Vanzant E.S. 2004. Suitability of a GPS collar for grazing studies. Trans ASAE 47:1321-9.

Anderson D.M. 2000. The cyber cow whisperer and his virtual fence. Agr. Res. 48:4-7.

Barbari M., Conti L., Koostra B.K., Masi G., Sorbetti Guerri F., Workman S.R. 2006. The use of global positioning and geographical information systems in the management of extensive cattle grazing. Biosyst. Eng. 95:271-80.

Bassignana M. 2005. Politiche agricole e alpeggi. Environment 30:39-42. Clark P.E., Douglas E.J., Kniep M.A., Jermann P., Huttash B., Wood A., Johnson M., McGillivan C., Titus K. 2006. An advanced, low cost, GPS based animal tracking system. Rangeland Ecol. Manag. 59:334-40.

Davis J.D., Darr M.J., Xin H., Harmon J.D., Russell J.R. 2011. Development of a GPS herd activity and well-being kit (GPS HAWK) to monitor cattle behavior and the effect of sample interval on travel distance. Appl. Eng. Agric. 27:143-50. 
Ganskopp D. 2001. Manipulating cattle distribution with salt and water in large arid land pastures: a GPS/GIS assessment. Appl. Anim. Behav. Sci. 73:251-62.

ION (Institute of Navigation Standards). 1997. ION STD 101: Recommended test procedures for GPS receivers. Institute of Navigation Standards, Alexandria, VA, USA.

Moen R.A., Pastor J., Cohen Y., Schwartz C.C. 1996. Effects of moose movement and habitat use on GPS collar performance. J. Wildlife Manage. 60:659-68.

National Agricultural Statistics Service (NASS). 2006. Cattle death loss. Agricultural Statistics Board, U.S. Department of Agriculture, Washington D.C., USA.

Pandey V., Kiker G.A., Campbell K.L., Williams M.J., Coleman S.W. 2009. GPS monitoring of cattle location near water features in South Florida. Appl. Eng. Agric. 25:551-62.

Rempel R.S., Rodgers A.R. 1997. Effects of differential correction on accuracy of a GPS in animal location system. J. Wildlife Manage. 61:525-30.

Sibbald A.M., Gordon I.J. (eds.). 2001. Tracking animals with GPS. pp 1-
113 in International Conference, Macaulay Land Use Research Institute, Aberdeen, UK.

Siror K.J., Sheng H., Wang D., Wu J. 2009. Use of RFID technologies to combat cattle rustling in the East Africa. pp 1556-62 in Proc. 5th International Joint Conference on INC, IMS and IDC, Seoul, Korea. Stombaugh T.S., Shearer S.A., Fulton J. 2002. Elements of a dynamic GPS test standard. In: ASAE Annual International Meeting. ASAE, St. Joseph, MI, USA, Paper N.021150.

Thurner S., Neumaier G., Wendl G. 2011. Management of young cattle on alpine pastures using a GPS-based livestock tracking system. pp 103-105 in Proc. 16th Symp. of the European Grassland Federation. Agricultural Research and Education Centre (AREC) RaumbergGumpenstein, Irdning, Austria.

Turner L.W., Udal M.C., Larson B.T., Shearer S.A. 2000. Monitoring cattle behavior and pasture use with GPS and GIS. Can. J. Anim. Sci. 80:405-13.

Umstatter C. 2011. The evolution of virtual fences: a review. Comput. Electron. Agr. 75:10-22. 